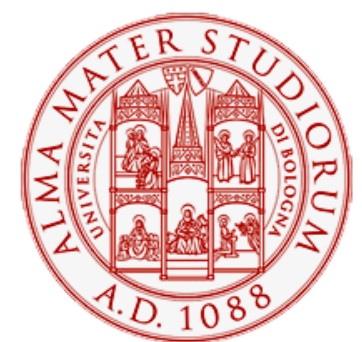

Alma Mater Studiorum - Università di Bologna DEPARTMENT OF ECONOMICS

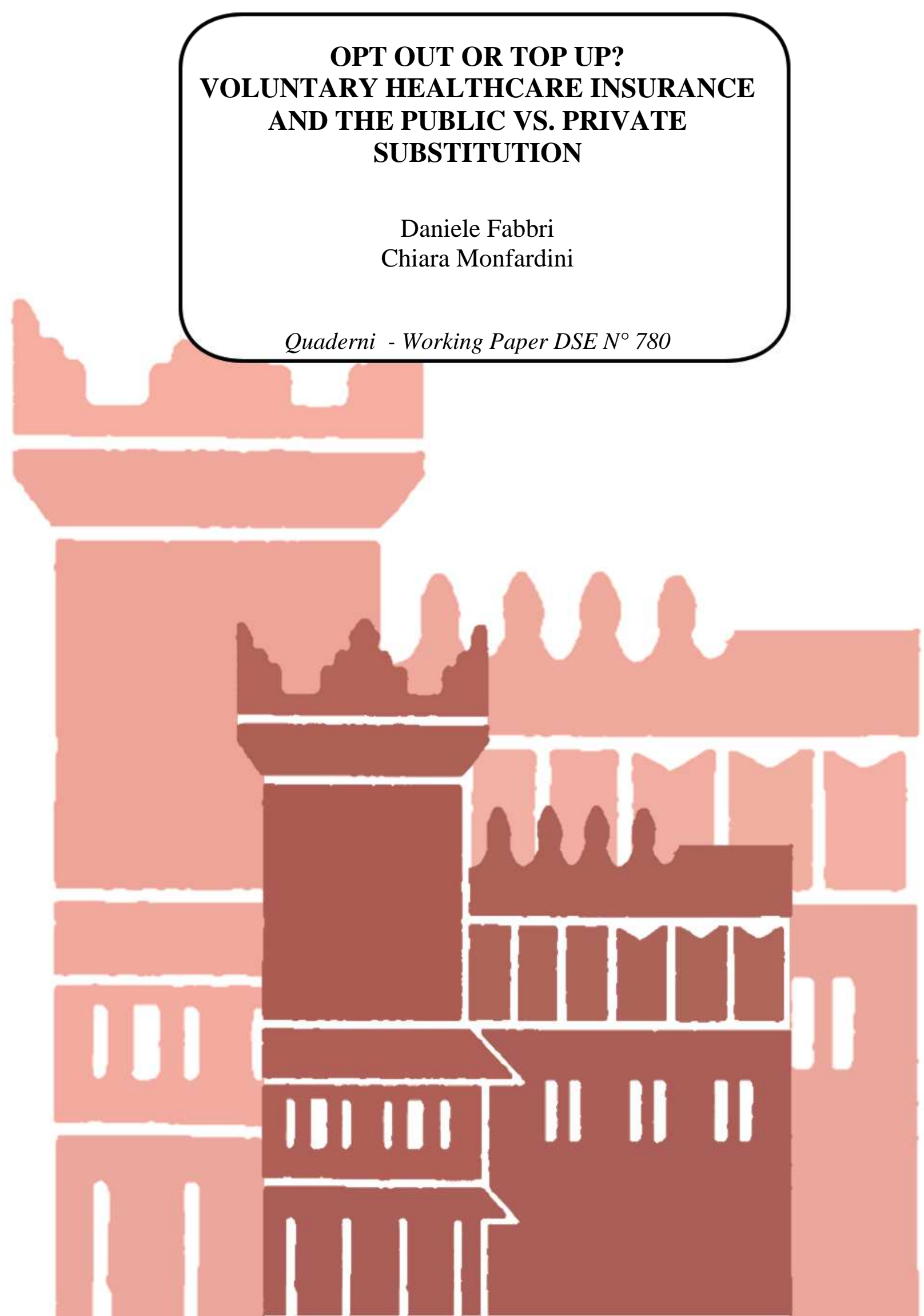




\title{
OPT OUT OR TOP UP? \\ VOLUNTARY HEALTHCARE INSURANCE AND THE PUBLIC VS. PRIVATE SUBSTITUTION
}

\author{
Daniele Fabbri \\ Dipartimento di Scienze Economiche - Università di Bologna, \\ CHILD, HEDG \\ Chiara Monfardini \\ Dipartimento di Scienze Economiche - Università di Bologna, \\ CHILD, HEDG, IZA
}

\begin{abstract}
August 2011
ABSTRACT:

We investigate whether people enrolled into voluntary health insurance (VHI) substitute public consumption with private (opt out) or just enlarge their private consumption, without reducing reliance upon public provisions (top up). We study the case of Italy, where a mixed insurance system is in place. To this purpose, we specify a joint model for public and private specialist visits counts, and allow for different degrees of endogenous supplementary insurance coverage, looking at the insurance coverage as driven by a trinomial choice process. We disentangle the effect of income and wealth by going through two channels: the direct impact on the demand for healthcare and that due to selection into VHI. We find evidence of opting out: richer and wealthier individuals consume more private services and concomitantly reduce those services publicly provided through selection into for-profit VHI. These results imply that the market for VHI eases the redistribution from high income (doubly insured) individuals to low income (not doubly insured) ones operated by the Italian National Health Service (NHS). Accounting for VHI endogeneity in the joint model of the two counts is crucial to this conclusion.
\end{abstract}

J.E.L. classification: C34, C35, D12, H44, I11

Keywords: Public provision of private goods, health insurance, bivariate count data model, endogenous multinomial treatment, simultaneous equation modeling.

Acknowledgments: We are grateful to Francesca Barigozzi, Partha Deb, Simona Grassi, Astrid Kiil, Thomas Lifkin, Owen O'Donnell, Pravin Trivedi and participants of seminars in Lausanne, Darmstadt, and Ithaca (ASHE-2010) for useful comments and suggestions. Usual disclaimers apply. 


\section{INTRODUCTION}

The appropriate relative sizes and roles of public and private sectors in financing healthcare are under debate in many countries. Countries that rely upon public financing are considering an expanded role for private healthcare finance as a way to reduce pressure on public budgets. This push, quite often, comes through a carrot-and-stick strategy. Reduction in coverage by statutory health insurance (SHI) and increased reliance on rationing-bywaiting force individuals to seek care in the private market. Besley et al. (1999) suggest that waiting time to access public provisions is a relevant determinant of the demand for voluntary health insurance (VHI) in England (see also Foubister et al. (2006)). Aarbu (2010) indicates this as the mechanism behind the rapid increase in private insurance coverage in Norway. At the same time, relaxing regulations on access to private health insurance and introducing tax deductions and incentives to buy supplementary coverage might ease the process. Recently, in Canada a 2005 Supreme Court decision abolished a law prohibiting complementary private insurance (Cuff et al. (2010)). Srivastava and Zhao (2008) document that Australia, in the late nineties, introduced several incentives and penalties to stem erosion in VHI. Similarly, a large use of tax incentives for the purchase of VHI is observed in Portugal, since 1999, and Ireland, since the 1970s (see Mossialos and Thomson (2004)).

However, concerns about tax incentives, to promote the take-up of VHI, being regressive, expensive and ineffective in stimulating demand, led, in recent years, to a clear trend towards abolishing or reducing their use. Tax incentives are, quite likely, to be regressive, provided that subscribers, most of the time, are in the upper tail of income distribution. This effect is even larger if, as noted by Davies (1999), tax relief is applied at the marginal tax rate. Moreover, effectiveness is also questionable whenever incentives compensate individuals, with VHI that may be paying for better amenities, without reducing their consumption of statutory healthcare. Mossialos and Thomson (2004) notice that reduction in tax incentives, devoted to encouraging VHI, occurred in Austria, Greece, Ireland, Italy, Spain and the UK.

This policy debate centers on two general arguments. Advocates of parallel private finance, argue that increasing private financing in healthcare can be beneficial to society: it would reduce demand pressure on the public provisions thus freeing resources to improve quality and to ease access to needed care. Opponents, on the other hand, dispute that private 
finance, by drawing resources away from the publicly financed system, would produce exactly the opposite. Much of the issue stands along the empirical value of the Besley and Coate (1991) conjecture. According to it, the public provision of healthcare can work as a redistributive device, whenever low income citizens choose the publicly provided good, while high income citizens, who contribute to subsidizing the public supply through income taxes, decide to opt out to the private sector. VHI might strengthen the redistributive role played by the SHI, as far as richer individuals are also more inclined to buy supplementary health insurance, thus, being less cost conscious when they consume private healthcare supplements.

We investigate the redistributive role of VHI in Italy, where a prominent share of the healthcare supply is publicly provided by the National Health Service (NHS), and about $21 \%$ of the population is covered by some form of VHI. Our research question is, whether people enrolled into VHI substitute public consumption with private (i.e. opt out) or, alternatively, they just enlarge their private consumption, without reducing reliance upon public provisions, (i.e. top up). To this purpose, we model the joint demand for public and private healthcare visits, accounting for the endogeneity of health insurance status. We consider different degrees of endogenous supplementary insurance coverage, looking at it as driven by a trinomial choice process. We distinguish between not-for-profit (NFP) VHI and for profit (FP) VHI. The resulting modeling framework is a simultaneous equation system with multinomial endogenous treatment. This represents a contribution to the literature on count data models which has either developed methods to address the endogeneity of a multinomial treatment in a single equation approach (see, for example, Deb and Trivedi (2006), for a simulation based classical estimation approach, or Munkin and Trivedi (2008), for a Bayesian analysis) or has jointly specified multiple equations sharing a common binary endogenous variable (see, for example, Zimmer and Trivedi (2006), for a Copula based estimation, or Chai Cheng and Vahid (2010), for a simulation based classical estimation approach). Our generalization to multiple equations is of particular relevance. Since the insurance regressors are endogenous in both count equations, ignoring their bivariate nature and estimating separately two univariate counts with endogenous treatment would lead to invalid inference on the treatment effects and other parameters of interest.

We find that having FP VHI coverage increases the demand for private visits, concomitantly reducing demand for public visits. The substitution effect prevails on the 
direct effect exerted by income and wealth on healthcare consumption. This implies that the better-off individuals, who more frequently buy VHI coverage, opt out of the public provision, so that the Italian NHS redistributes, from high income to low income individuals, through the operation of the VHI market. We prove that selection effects into VHI, due to unobservables, are substantial in our case study. Allowing for the endogeneity of insurance status is crucial for the inference on healthcare insurance effects and other key parameters on which the answer to our research question relies. Under exogeneity, the results would imply the opposite conclusion that the more affluent individuals top up rather than opt out.

The paper is organized as follows. The next section presents the econometric model. Section 3 provides a concise institutional background on the Italian NHS, the market for voluntary insurance and the market for physician care in Italy, introducing at the same time the dependent variables of our model. Section 4 describes the data. Section 5 presents the empirical specification and illustrates the estimation results. Section 6 concludes.

\section{A BIVARIATE COUNT DATA MODEL WITH ENDOGENOUS MULTINOMIAL TREATMENT}

Our econometric model comprises two blocks of equations: a trinomial insurance choice model (treatment equations), and a bivariate count data model for the PUBLIC and PRIVATE visit (outcome equations), in which the insurance status is allowed to be endogenously determined. We follow the approach of Deb and Trivedi (2006), and account for self-selection into insurance status by resorting to a latent factor structure. However, we extend their model, which includes a single outcome equation, to the case of the joint modeling of two outcome equations. From the economic side, this bivariate SURE framework is invoked by our main research question, aimed at measuring to what extent, being privately insured leads to a substitution of public with private consumption. From the econometric perspective, our bivariate model with endogenous treatment represents the proper setting for valid inference. Indeed, when multiple outcomes are simultaneously determined and there is a common endogenous variable, reduction to a single equation model with endogenous regressor leads to inconsistent estimates of the treatment effects and other parameters of interests in the outcome equation. In our case study, public and private visit count equations are certainly linked via correlation of unobservable factors such as the frailty condition- that cannot be completely controlled for with individual 
characteristics available in the data (Fabbri and Monfardini (2009) find a positive residual correlation between the two health outcomes).

Let $y_{h i}=0,1,2, \ldots$ be the number of visits of type $h$ consumed by the individual $i$, with $h=P U B, P R I V$, and let the $d_{i j}$ binary variables indicating whether the individual chooses the $j$-th insurance status alternative ( $d_{i j}=1$ if alternative $j$ is chosen; $d_{i j}=0$ otherwise), where the set of mutually exclusive insurance statuses is given by:

$j=0$ : no VHI (only statutory health insurance);

$j=1$ : NFP VHI ONLY (doubly insured with NFP VHI only);

$j=2$ : FP VHI (doubly insured with FP VHI and possibly NFP VHI) ${ }^{1}$.

The indirect utilities, associated with the three alternatives, are defined as:

$$
\begin{aligned}
& u_{i 0}=w_{i} \alpha_{0}+\eta_{i 0} \\
& u_{i 1}=w_{i}^{\prime} \alpha_{1}+\delta_{1} \ell_{i 1}+\eta_{i 1} \\
& u_{i 2}=w_{i} \alpha_{2}+\delta_{2} \ell_{i 1}+\eta_{i 2},
\end{aligned}
$$

where $w_{i}$ is a set of individual specific regressors, $\eta_{i j}$ are $i . i . d$ and follow a type 1 extreme value distribution (leading to multinomial logit model), $\ell_{i 1}$ is a latent factor representing unobserved tastes for voluntary insurance, standard normal i.i.d. and independent of $\eta_{i j}$. For identification we restrict $\alpha_{0}=0$, i.e. $j=0$ is made the reference state, and we set $\delta_{1}=\delta_{2}=1$ to normalize the scale of the latent factor. Notice that this structure makes the composite errors, of the utilities associated to alternatives 1 (NFP VHI) and 2 (FP VHI), correlated via the common error component $\ell_{i 1}$. This is a reasonable pattern, since alternatives 1 and 2 encompass a common choice, i.e. not-for-profit insurance can be owned simultaneously with a private one. ${ }^{2}$

The assumptions above define the following mixed multinomial logit structure for the insurance status probabilities:

\footnotetext{
${ }^{1}$ We are forced to collapse the doubly insured with both FP and NFP VHI into this class since the former group represents only the $2.4 \%$ of our sample.

${ }^{2}$ Another possibility would be to estimate a free correlation parameter between utilities associated to alternatives 1 and 2. However, identification of this parameter requires alternative specific regressors that are not available in our case study.
} 


$$
\begin{aligned}
& \operatorname{Pr}\left(d_{i 0}=1 \mid w_{i}, \ell_{i 1}\right)=\frac{1}{1+\sum_{m=1,2} \exp \left(w_{i}^{\prime} \alpha_{m}+\ell_{i 1}\right)} \\
& \operatorname{Pr}\left(d_{i j}=1 \mid w_{i}, \ell_{i 1}\right)=\frac{\exp \left(w_{i}^{\prime} \alpha_{j}+\ell_{i 1}\right)}{1+\sum_{m=1,2} \exp \left(w_{i}^{\prime} \alpha_{m}+\ell_{i 1}\right)} \quad j=1,2
\end{aligned}
$$

Coming to the outcomes block of the model, we use a Poisson-Normal mixture, assuming that each count $y_{h i} h=P U B, P R I V$, is independently driven by a Poisson process, conditionally to the vector of covariates $z_{i}, d_{i 1}, d_{i 2}$ and to the couple of latent factors $\ell_{i 1}$, $\ell_{i 2}$; where the second unobservable factor $\ell_{i 2}$ is normal i.i.d and independent of $\ell_{i 1}:{ }^{3}$

$$
f_{h}\left(y_{h i} \mid z_{i}, d_{i 1}, d_{i 2}, \ell_{i 1}, \ell_{i 2}\right)=\frac{\exp \left(-\mu_{h i}\right) \mu_{h i}^{{ }^{y_{h i}}}}{y_{h i} !} \quad h=P U B, P R I
$$

The conditional means of the two Poisson processes are:

$$
\mu_{h i}=E\left(y_{h i} \mid z_{i}, d_{i 1}, d_{i 2}, \ell_{i 1}, \ell_{i 2}\right)=\exp \left(z_{i}^{\prime} \beta_{\text {Zh }}+\beta_{1 h} d_{i 1}+\beta_{2 h} d_{i 2}+\lambda_{1 h} \ell_{i 1}+\lambda_{2 h} \ell_{i 2}\right)
$$

Since both latent factors are heterogeneity components common to the two counts, they are the source of their simultaneous determination. The first component, $\ell_{i 1}$, captures selection effects into insurance choice: an agent might choose to own any supplementary insurance based on unobservables that also determine simultaneously his choice of public versus private health care. Therefore, the parameters $\lambda_{1 h}$ measure the covariance between the unobservables, entering the utility associated to supplementary insurance choices, and the expected visit consumption $h$. A positive $\lambda_{1 P R I V}$ implies that unobservables increasing the probability of choosing a voluntary insurance - either not-for-profit or for-profit - will also increase private visit consumption. A similar interpretation applies to $\lambda_{1 P U B}$. The second component, $\ell_{i 2}$, captures co-movements in public and private visit counts that are not channeled through insurance choice behavior. We set $\lambda_{2 P U B}=0$ since only one of the parameters $\lambda_{2 h}$ is identified, so that $\lambda_{2 P R I V}$ will measure the covariance between PUB and

\footnotetext{
${ }^{3}$ We mix the normal latent factor with a Poisson distribution rather than a Negative Binomial one. In this way we avoid a further overdispersion source in the model besides that arising from the latent factor. We experimented problems in identifying the additional overdispersion parameter when using a normal-NB mixture. We are grateful to Partha Deb for pointing out, to us, this problem.
} 
PRIV visits, conditional on observables characteristics $z$ and insurance status.

This framework allows us to disentangle the insurance treatment effects on visits of type $h$, $\beta_{1 h}, \beta_{1 h}$, from the possible selection effect for the two types of visits (adverse or positive selection on unobservables). The model encompasses a bivariate count model with exogenous insurance, when $\lambda_{1 P R I V}=\lambda_{1 P U B}=0$.

Given that the two counts are independent, conditionally on the latent factors, their bivariate joint distribution is given by:

$$
f\left(y_{i} \mid z_{i}, d_{i}, \ell_{i} ; \beta, \lambda\right)=\prod_{h \in(P U B, P R I)} f_{h}\left(y_{h i} \mid z_{i}, d_{i 1}, d_{i 2}, \ell_{i 1}, \ell_{i 2}\right)
$$

where vectors $\beta, \lambda$ collect the parameters of both the public visits and the private visits equations, and $d_{i}=\left(d_{i 1}, d_{i 2}\right), \ell_{i}=\left(\ell_{i 1}, \ell_{i 2}\right)$.

Let us introduce the short notation, $\operatorname{Pr}\left(d_{i} \mid w_{i}, \ell_{i 1}\right)$, for the mixed logit probabilities of treatment introduced above. The likelihood of the model is derived with two steps. First, conditionally on the latent factor, the joint distribution of insurance and visit count variables is obtained from the usual conditional by marginal density factorization. Second, the unobserved latent factors are integrated out:

$$
\begin{aligned}
\operatorname{Pr}\left(y_{i}, d_{i} \mid w_{i}, z_{i}\right) & =\int f\left(y_{i} \mid z_{i}, d_{i}, \ell_{i}\right) \operatorname{Pr}\left(d_{i} \mid w_{i}, \ell_{i 1}\right) h\left(l_{i}\right) d \ell_{i}= \\
& =\int \prod_{h \in(P U B, P R I)} f_{h}\left(y_{h i} \mid z_{i}, d_{i}, \ell_{i}\right) \operatorname{Pr}\left(d_{i} \mid w_{i}, \ell_{i}\right) h\left(l_{i}\right) d \ell_{i}
\end{aligned}
$$

Since the integral above has not closed solution, estimation is performed by maximizing a Simulated Likelihood (Gourieroux and Monfort (1996)), which approximates the expected value with an average over $R$ pseudo-random draws:

$$
L^{R}=\frac{1}{R} \sum_{r=1}^{R} \prod_{h \in(P U B, P R I)} f_{h}\left(y_{h i} \mid z_{i}, d_{i}, \ell_{i}^{r}\right) \operatorname{Pr}\left(d_{i} \mid w_{i}, \ell_{i}^{r}\right)
$$

The resulting Simulated Maximum Likelihood Estimator is close to the MLE provided R is sufficiently large. We follow the guidelines which emerged from the literature concerning the use of Halton sequences, rather than pseudo-random values, in order to reduce the 
variance of the simulated likelihood and to speed up convergence (Bhat (2001); Train (2002)). We find that $R=2000$ leads to stable results, corroborating the experience of other research on models involving endogenous dummies like ours (see Deb and Trivedi (2006)). Both the generation of the Halton sequences, and the maximization of the simulated likelihood have been performed within STATA 11 (lf method).

The Poisson specification we adopt for modeling the visit processes is quite convenient for analyzing treatment effects and demand elasticities. When the mean function is like $\mu=E(y \mid x)=\exp \left(\gamma^{\prime} x\right)$, the elasticity of the count, with respect to a continuous variable regressor $x_{k}$, is given by:

$\varepsilon_{k}=\frac{\partial E(y \mid x)}{\partial x_{k}} * \frac{x_{k}}{E(y \mid x)}=\gamma_{k} x_{k}$

The evaluation of the treatment effect of each insurance dummy amounts, instead, to a semi-elasticity and is given by the corresponding coefficient.

\section{THE BACKGROUND OF OUR CASE STUDY}

In this section we present basic institutional backgrounds on the Italian NHS, the market for VHI and the market for specialist consultations. We refer to the situation prevailing in the year 2000, for which we conduct our empirical exercise. Despite major reforms which took place thereafter, most of the features referred to the market for insurance and those for consultations are still valid.

\subsection{THE ITALIAN NHS}

The Italian NHS provides comprehensive statutory insurance and uniform healthcare to the entire population. Under the Italian Constitution, the State has exclusive power to set the "essential levels of care" to be made available to all residents throughout the country. Regions have exclusive responsibility for the organization and administration of publicly financed healthcare. NHS is mainly financed by general taxation. Funds are transferred from the central government to each region, according to a capitation rule, and then reallocated among approximately 200 Local Health Authorities (LHAs). Within its budget, each LHA is responsible for financing healthcare consumption of the "enrolled" population, being also (mainly) responsible for healthcare production. Depending on a citizen's income, age and health condition, co-payments are also charged for drugs, out-patient treatments, 
some diagnostic and laboratory tests, and medical appliances.

The political allocation rules for public healthcare provisions will necessarily leave some people, those at the extremes of the preference distribution, unsatisfied. Publicly-financed national health services, almost inevitably, generate a willingness to pay for additional private services, whose consumption opportunities might be enlarged by way of VHI underwriting. Notice that in the Italian NHS there is no way to unsubscribe from the SHI, as in Germany, for instance, so that "ends against the middle" equilibrium (Epple and Romano (1996)) cannot emerge except through an impoverishment of public supply.

\subsection{THE MARKET FOR INSURANCE}

According to Italian law, citizens can enlarge their SHI coverage in two ways: buying a VHI policy supplied in the commercial insurance market (FP VHI) and obtaining some additional coverage by joining into a mutual insurance company (NFP VHI). Mutual insurance companies are entirely owned by their policyholders. Group solidarity, limited profit sharing, absence of shares and free membership are their distinct traits.

These two types of VHI play a mixed role with respect to the SHI. Both of them grant coverage for consumption of "complementary" and "supplementary" types of provisions. According to common definitions in the literature, a provision is said to be complementary if it refers to services already provided by the SHI, while it is said to be supplementary if it is not granted under the SHI policy. Both markets are almost completely unregulated except for some requirements concerning financial stability.

Despite the types of provisions which are not qualitatively different, coverage granted by FP VHI is larger and more complete. Contributions and premiums are concomitantly higher in FP plans. In the year 2000, the average contribution to mutual insurances was about 290 Euros per year, ranging from a minimum of about 85 to a maximum of 660 . Corresponding figures in the FP VHI plans are about 995 Euros (minimum 500 and maximum 2400).

\section{Insert Table 1 here}

Table 1 displays the distribution of health insurance status in our sample, which comes from "Indagine Statistica Multiscopo sulle Famiglie: condizioni di salute e ricorso ai servizi sanitari 1999-2000", conducted by the Italian National Institute of Statistics, ISTAT, and it is representative of Italian males, aged above 18 (see Section 4, for a description of our sample selection criteria). Despite the fact that the vast majority of the individuals, 
amounting to $79 \%$, is covered only from SHI, the shares of people resorting to VHI, either NFP or FP is considerable ( $9.6 \%$ and $11.4 \%$, respectively).

\subsection{THE MARKET FOR SPECIALISTS' VISITS}

The Italian NHS plays a major role in the market for specialist consultations where, public, closely regulated and mainly salaried specialists, compete with private, less strictly regulated ones. Specialized NHS out-patient services, including visits, diagnostics and treatment, are provided, either by the LHA's salaried specialists or by accredited public and private facilities, with which the LHA has agreements and contracts. A co-payment, discretionary for each region up to a ceiling determined by national law, is required. Since these ceilings are well below the market clearing level, queues of patients form, and supply is rationed.

Because of waiting lists, co-payments and unsatisfactory quality, many patients seek care outside the NHS, resorting to the private market for specialist care. This market is quite well developed. Private specialists are subject to an authorization, based on minimum standard requirements, which turn out to be very loose indeed. Fees, quality and most other relevant features of private medical practices are mainly subject to market forces. As a result, it is generally true that the private alternative to NHS supply is higher priced and, for the class of specialist visits we consider here, i.e. excluding hospital out-patient visits, of better quality.

\section{Insert Table 2 here}

Table 2 shows the two public and private visits' counts that will be the key dependent variables in our model. They include all the specialist consultations except dental care, aggregated into a single class of visits within each type of provider, and consumed in the span of a month. Low participation rates (5.5\% for public visit, $4.6 \%$ for private ones) are therefore implied.

\subsection{TAX DEDUCTION}

Concerning tax incentives, in the year $200019 \%$ of the contributions to NFP VHI were tax deductible up to a ceiling of 1200 Euro, at the individual average tax rate. No deduction was granted for premiums paid to a FP VHI plan and this is, currently, still the case. At the same time, notice that $19 \%$ of the cumulated out-of-pocket (OOP) payments above a minimum of about 110 Euros, is tax deductible. For those covered by a FP VHI, deduction 
is granted also for the part of OOP payments that have already been refunded by the insurance company. This arrangement tends to produce an incentive to adversely select into FP VHI. Frail individuals, those who foresee themselves consuming more, would receive the same tax incentive to subscribe a NFP VHI as the healthier individuals. While tax deduction for OOP payments, on top of FP VHI refunds, makes these plans more attractive for the unhealthy, rather than for the healthier, subscribers.

\section{DATA}

Data come from "Indagine Statistica Multiscopo sulle Famiglie: condizioni di salute e ricorso ai servizi sanitari" conducted by ISTAT. We use the 1999-2000 survey which is the most recent available cross-section where information on an individual's insurance status is collected. The full sample contains 52,332 households (140,011 individuals). The survey focuses on individual healthcare consumption in the 4 weeks before the interview. Individuals are also asked about the amount of money paid out-of-pocket and waiting time for obtaining their last visit.

In our data the insurance status is defined as individual "coverage" from private VHI. We restrict our analysis to male householders $(\mathrm{HH})$, aged 18 or above (38,719 observations). In this sample, coverage and ownership both tend to coincide. We also drop individuals that are hardly insurable: those above 70 years of age, and those affected by severe chronic conditions (Parkinson's disease, mental and nervous diseases). Finally, we select out observations with degenerate values on INCOME and missing values on FEES (see the regressors' description below in Section 5), and are left with a final estimation sample made up of 27,945 observations.

\section{Insert Table 3 here}

Table 3 provides a preview on the relationship between insurance status and healthcare consumption. The overall consumption proves to be quite homogenous across the three groups. What clearly matters is the composition in public versus private provision; the larger is coverage, the lower is reliance upon public provision and, concomitantly larger, is the use of privately supplied visits. This pattern is confirmed by the marginal effects of being covered by each class of VHI on the average consumption of visits, estimated with no controls and reported in the lower part of the table. 


\section{EMPIRICAL SPECIFICATION AND RESULTS}

\subsection{REGRESSORS}

Our specification of the insurance choice and the visit count models relies upon Fabbri and Monfardini (2009). It fully exploits the rich set of information available in the ISTAT dataset described above and comprises most covariates that are used in empirical analyses of healthcare consumption with endogenous insurance (e.g. Cameron and Trivedi (1988); Holly et al. (1998); Buchmuller et al. (2004); Deb and Trivedi (2006); Munkin and Trivedi (2008)). The block of regressors, which is common to the insurance and the utilization equations (or enter only the latter - and therefore do not play any role for identification of the insurance dummies coefficients), consists of the following sets of variables.

Health conditions variables, aimed at measuring individual risk factors, include: EXEMPT, a dummy identifying those individuals who are entitled to free public specialist visits due to health or economic status; measures of chronic conditions or physical limitations such as INVALID, CHRONIC (dummy), NCHRONIC (number of chronic conditions), LIM ADL (dummy indicating limitations in the daily activities; SRH good, a dummy indicating whether the self-perceived general health status is declared to be good or very good.

The set of socio-demographics covariates consists of a quadratic specification for AGE, a dummy identifying MARRIED individuals, and two education dummies: MEDIUM EDUC (if the person holds a secondary school certificate), HIGH EDUC (if he/she holds a university degree). We also insert information on employment status and professional position, that might drive the insurance choice and at the same time capture differences in the individual value of time, through the dummy variables EMPLOYED, SELF-EMPL (self-employment), HIGH POSITION (high professional position), HIGH POSITION as SELF-EMPL (high position in self-employment). Individual economic variables, entering both the insurance and the utilization equation, comprise a dummy, indicating HOME OWNERSHIP and the household disposable INCOME. ${ }^{4}$

An important group of regressors is, instead, measured at the level of the Local Health Authority (LHA), which is taken as the proper relevant market area for medical

\footnotetext{
${ }^{4}$ This measure is derived from a matching exercise performed by the Italian National Statistical Institute, as the ISMF survey does not have data on household income. By regression matching, each household in the sample was assigned the imputed after-tax monthly income, estimated using data from the Survey on Household Income and Wealth, conducted by the Bank of Italy. This measure is then equalized and deflated with household monthly food expenditure at LHA level (see Fabbri and Monfardini (2009)).
} 
consultation. For a detailed description of these measures, see Fabbri and Monfardini (2009), where they have been proposed and developed. A first subset of such regressors is common to both insurance and visits equations and captures the overall quality and availability of healthcare services supplied by the LHA. These variables include the public expenditure per-capita in the LHA, PUBLIC EXP; the PHYSICIAN DENSITY, providing a measure of the availability of doctors in the local area; the waiting time to access the two different types of consultation (we insert both variables WAIT PUBLIC and WAIT PRIVATE in the visit equation ${ }^{5}$ and a dummy indicating if the waiting time for public is greater than that for a private visit, HIGH DIFF IN WAIT in the insurance model).

A second subset of variables, at the LHA level, enters the visit equations only. This is meant to control for equilibrium conditions in the local healthcare market. Among these variables, we include public and private visit fees faced by consumers, FEE PUBLIC and FEE PRIVATE; the PRICE of a NON-FOOD BUNDLE (which is needed to fulfill the requirements of a coherent, incomplete system of demand); Finally, to better describe the context in which the agents make their choices and to control for other sources of geographical variation in healthcare and insurance markets we insert geographical fixed effect in the form of regional dummies, and a dummy for individual residing in provincial capital, CHIEF TOWN.

\subsection{EXCLUSION RESTRICTIONS}

The key regressors of the two visit equations, are the treatment variables represented by the insurance dummies: NFP VHI only and FP VHI. To deal with their endogeneity and to achieve identification of the associated causal parameters in the outcome equations, we rely upon a set of exclusion restrictions. We propose a set of instrumental variables that are determinants of the insurance choice but plausibly do not enter the utilization part of the model under the specification outlined above. ${ }^{6}$ The first source of exclusion restrictions we rely upon is quite uncommon in this stream of empirical studies. We take advantage of the availability of individual premiums paid for FP VHI in another Italian survey, SHIW (Survey on Household Income and Wealth), conducted by the Bank of Italy. Adopting a regression matching procedure, we generate the premium that each individual of our

\footnotetext{
${ }^{5}$ Fabbri and Monfardini (2009) argue that, using the full vector of LHA specific waiting times allows to control for the probability of data truncation. Indeed, due to the four week recall period, we might fail to observe the full record of individual visits related to a single spell of illness.

${ }^{6}$ These instrumental variables are needed beyond the non-linear functional form of the model to achieve robust identification.
} 
sample expects to pay for underwriting a FP VHI plan (variable PREMIUM). This variable incorporates exogenous shifters in the supply of insurance arising from geographic variation in the market of healthcare insurance. ${ }^{7}$ The additional instrumental variables we posit are referenced in the literature: the presence of dependent children in the household, which might affect the propensity to buy additional insurance coverage (CHILDREN, a dummy indicating the presence of kids under 18, and \#CHILDREN, their number), and a set of dummies for the employment sector (AGRICULTURE, RETAIL TRADE, TRANSPORTS, PROFESSIONAL SERVICES, PUBLIC ADMINISTRATION, EDUCATION). Our argument is that, different employment sectors offer different opportunities to enroll into a VHI and also attract individuals with different degrees of risk aversion. ${ }^{8}$ We checked the relevance of the whole set of instruments in the health insurance model, strongly rejecting the assumption of their coefficients being jointly equal to zero.

\section{Insert Table 4 here}

\subsection{UTILIZATION RESULTS: TREATMENT AND SELECTION EFFECTS}

Table 5 provides the estimated coefficients on the insurance dummies, both under the null of exogeneity and then by accounting for endogeneity. Under exogeneity, being insured does not affect the consumption of public visits, irrespective of the type of insurance coverage. On the other hand, being covered by FP VHI, with respect to not being doubly insured, exerts a significant positive impact on consumption of private visits. Such a positive impact, attributable to switching from not being doubly insured to being covered by FP VHI, is quite large, i.e. about $42 \%$. Once we allow for endogeneity of insurance status, we find that selection effects in VHI, due to unobservables, are substantial in our

\footnotetext{
${ }^{7}$ The premium prediction is obtained by estimating a Heckman model on a set of regressors that are common to the two data sources such as gender, age, macro-area of residence, dimension of the municipality of residence. The latter two variables capture exogenous geographical variation in the supply side of the local market faced by the individual, and are assumed to determine the insurance choice only through their effect on the local market premium. Occupational sector dummies are the extra regressors needed in the selection equation of the Heckman model, following arguments explained in the following main text. The instrumental variable PREMIUM we use is the individual unconditional expectation evaluated with the estimated Heckman model.

${ }^{8}$ The occupational sector dummies are used to generate exclusion restrictions, both in our insurance choice model and in the selection equation of the Heckman model on which premium prediction is based (see previous note). We checked that the coefficients on sector dummies in our main model are almost unchanged when we exclude the variable PREMIUM from the specification. This lack of collinearity between PREMIUM and occupational variables is explained with the fact that premium prediction is the unconditional expectation in the Heckman model, and these variables do not enter into it through their linear combination.
} 
case study and crucial for the inference on treatment effects and other parameters of interest. The impact of being covered by FP VHI on private consumption is now a large +92\%. This larger impact hinges upon substitution for the public visits, which are reduced by $-135 \%$. Concerning the impact on the demand for public visits, according to our estimates, while being covered by NFP VHI has no effect under exogeneity, it leads to a large reduction (-117\%) in the consumption of this class of visits, if endogeneity is allowed for. Under endogeneity, the insurance effects are estimated, controlling for unobservable characteristics simultaneously affecting the two visit counts and the choice of insurance coverage. According to our estimates, the unobservables that increase the probability of being doubly insured, raise the consumption of public visits while decreasing that of private ones. Somehow, we have a mixed pattern of adverse and favorable selection into insurance. A possible candidate for this pattern is individual risk aversion. Private specialist visits, indeed, are priced according to a more cumbersome and variable schedule. Thus risk averse individuals may be more willing than average to doubly insure and, simultaneously, rely less on private visits. ${ }^{9}$

\section{Insert Table 5 here}

\subsection{UTILIZATION RESULTS: DEMAND ELASTICITIES}

The regressors' coefficients (see table A1) are, with few exceptions, quite precisely estimated and consistent with previous empirical evidence on the determinants of visits counts (Pohlmeier and Ulrich (1995); Deb and Trivedi (1997, 2002); Fabbri and Monfardini (2003); Atella and Deb (2008)). Within our specification, the estimated demand elasticities represent partial demand responses to a small perturbation of the equilibrium in the local market for public and private consultancy (see Fabbri and Monfardini (2009)). In particular, we can estimate a full set of (own- and cross-) price and waiting time elasticities.

Our results (see Table 6) suggest that the demand for public specialist visits is moderately price sensitive. The own-price elasticity we find, despite quite imprecisely estimated, is in the order of magnitude of those estimated in the literature (see the survey in Cutler (2002)). Namely, a $10 \%$ price increase reduces the average number of visits by $1.9 \%$. It is worth noticing that a pattern of substitution prevails between public and private specialist consultations. Cross price elasticities are both positive. The impact of private fees on public

\footnotetext{
${ }^{9}$ Schmitz (2011) provides direct evidence on risk aversion being responsible for favorable selection into insurance using data from GSOEP.
} 
demand is very imprecisely estimated, while the impact of public fees on private demand is quite large and significant. Administrative waiting time plays a less substantial role as a rationing tool for public visits, while it seems much more relevant for private visits, where the own-waiting time elasticity is about $-2.3 \%$.

Being exempt, suffering from chronic conditions or being limited in ADL results in the consumption of more visits: all these variables are proxies of individual health status. Stating to be in good or in very good health reduces demand of both classes of visits. It is worth noting that highly educated individuals do not consume more private visits, while intermediate educated individuals consume more private specialist visits to the same extent of public ones (the coefficients of both the educational dummies have very similar magnitude in the private visit equation). These results can be consistent with the view purported by the Grossman model, that more educated individuals demand more health but less services, in that they are more efficient and better informed as consumers. Being employed presumably picks up the effect of time constraints due to working: these individuals consume more private visits, especially if employed in a high position.

The direct effect of household income is never significant. On the contrary, our proxy for wealth (i.e. home ownership) exerts a significant and large positive impact on the demand for private visits. These patterns also hold under exogeneity of the insurance status. Therefore, by looking at the demand equations only and noticing that neither income nor wealth negatively affect the demand for public visits, we might be induced to consider the Besley and Coate (1991) conjecture (i.e. the richer opt out from the public provision) to be violated in our case study.

\section{Insert Table 6}

\subsection{INSURANCE CHOICE RESULTS}

Average marginal effects on insurance choice, of most of the regressors (see Table 7), are those expected. We find that a $10 \%$ increase in the individual local premium for a private VHI policy is associated with a $3.2 \%$ increase in the probability of being covered, just by the statutory health insurance. Concomitantly, the same increase is associated with a large reduction $(-17.8 \%)$ in the probability of being covered by a FP VHI, and a less dramatic drop $(-6.9 \%)$ in the probability of being covered by a NFP VHI. Coming to the effect of 
differential waiting times to access the local public provisions of specialist case, our evidence is mixed and somehow conflicting with results in the literature (see Besley et al. (1999)). We find some effect on the demand for NFP VHI, but not on the demand for FP VHI. Apparently, the willingness to obtain a double coverage on top of SHI revealed by the choice of FP VHI does not respond to relative longer waits in accessing the local public supply.

\section{Insert Table 7 here}

Highs and lows in the magnitudes of associations between income and wealth and type of coverage are consistent with theory: higher income and richer individuals are more willing to get larger insurance coverage. Notice that this is so, even after having partialled out the effects of education. These latter are, again, consistent with the expected higher propensity to get insurance coverage among the more educated. Being employed is associated with a significant increase in the probability of being covered by VHI. The association is larger in the case of coverage granted by NFP VHI only (+87\%), and by FP VHI (+27\%). A more similar association pattern, across the two VHI status, applies to the effect of high position at work (i.e. approximately $+50 \%$ ). On the other hand, being an entrepreneur or a selfemployed professional does not correlate with a larger probability of NFP coverage alone, while, it is associated with a large increase in the probability of being covered by FP VHI $(+101 \%)$.

Our proxies for health have, mostly, no significant marginal effects. Notice that the included characteristics are not used by the NFP insurer in setting contributions, nor in the definition of coverage, so that they might be considered as potential sources of asymmetric information. Therefore, it can be tentatively said that, the pool of individuals covered by a NFP VHI plan do not exhibit any compositional systematic difference in observed health risk factors unknown to the insurer. Our estimates of average marginal effects on insurance choice probabilities of being 1 year older (see Table 8), show some an increasing impact of age on enrolment into NFP VHI. This evidence could suggest that existing contribution to NFP VHI plans, which usually increases with age, does not discourage underwriting as individuals get older. Coming to enrolment into FP VHI, we find that the probability of coverage increases with both suffering from a chronic condition and being in good or very good self-rated health. Notice that this last characteristic is clearly unobservable to the insurer and has been shown to be a good predictor of future health conditions (see Idler and 
Benyamini (1997)). Since it can be considered as a proxy for private information on individual health, our finding points towards a slightly favorable selection into FP VHI.

\section{Insert Table 8 here}

\subsection{OPTING OUT OR TOPPING UP?}

According to our utilization results, neither income nor wealth have a direct negative effect on the demand for public visits. On the other hand, the insurance choice model estimates show that high income and richer individuals more frequently buy additional VHI coverage on top of SHI granted by the NHS. Provided that having a FP VHI coverage increases the demand for private visits and, concomitantly, reduces that for public visits, it can, therefore, be concluded that the Besley and Coate (1991) argument can be reestablished and qualified: the richer opt out from the public provision through a larger FP VHI underwriting.

\section{Insert Table 9 here}

To clarify this point, we sum up our evidence in Table 9, where a back-of-the-envelope calculation disentangles the direct and indirect effects of our proxies for income and wealth on public versus private consumption. We focus on the latter (i.e. house ownership), since results are more clear cut. According to estimates in Table 6, becoming a house owner increases the demand for public visits by $13.6 \%$ and the demand for private visits by $25 \%$. However, this direct effect is not the end of the story, since the impact on visits also goes through the probability of being insured and moral hazard effects, conditional on being insured. Becoming a home owner increases the average baseline probability of being doubly insured with FP VHI by 26 pp, while that with NFP VHI by 19 pp. The effect for being doubly insured with FP VHI is to consume $135 \%$ less public visits and $92 \%$ more private ones, while that for being doubly insured with NFP VHI is to consume $117 \%$ less public visits and $69 \%$ more private. Therefore, the indirect effect on public and private visits consumption, determined by a switch to being a house owner via FP VHI, amounts to $-35 \%$ and $+24 \%$ respectively, while that via NFP VHI is $-22 \%$ and $+13 \%$. Largely, despite the direct effect of owning a house on public visits being positive, the indirect effects via NFP and FP VHI are both negative, so that the overall impact turn into negative (i.e. $-44 \%$ ). On the contrary, direct and indirect effects, of becoming house owners, on private visits are both positive, with the overall impact being a large $62 \%$. The left part of Table 9 displays the same calculation under exogeneity. The direct effect of wealth on private visits is 
similar, while the indirect one is positive, despite being lower, with respect to the endogenous case. Quite remarkably, the indirect effects on private visits are now negligible, such that the total effect on private visits turns to be slightly positive. Therefore, under exogeneity, we would conclude in favor of topping up (i.e. the more affluent consuming larger quantities of the private supplements without reducing the consumption for the publicly provided private good). Allowing for the endogeneity of insurance status, notably, changes the picture in favor of the opting out hypothesis, thus implying that the more affluent do substitute the, lower quality, public provision for the superior private alternatives. Our modeling strategy proves to be crucial for answering this major question.

\section{CONCLUSIONS}

The public provision of a private good can work as a redistributive device. However, the availability of a voluntary private insurance might either strengthen or weaken the redistributive role played by the public provision of healthcare, in case adverse or favorable selection, respectively, prevails in the insurance market. We consider this issue and explore the impact of the endogenous selection mechanism into private voluntary insurance on visits consumption in the Italian NHS. In Italy about $21 \%$ of the population is doubly covered by some form of voluntary health insurance and a prominent share of the supply is publicly provided under statutory insurance. To gauge some hints upon the redistributive impacts produced by the Italian NHS, we jointly model the demand for both public and private healthcare demand accounting for the endogeneity of health insurance status, distinguishing between not-for-profit (NFP) VHI and for-profit (FP) VHI. The resulting modeling framework is a simultaneous equation system with multinomial endogenous treatment which represents a novel contribution o the existing literature on count data models. We show that having a FP VHI coverage increases the demand for private visits and, concomitantly, reduces that for public visits. We disentangle the effect of income and wealth by going through two channels: the direct impact on the demand for healthcare and that due to selection into VHI. Both of them suggest that richer and wealthier individuals consume more private services but do concomitantly reduce those publicly provided, only through selection into insurance status. These results imply that the market for VHI eases the redistribution from high income (doubly insured) individuals to low income (not doubly insured) ones operated by the Italian NHS. This is in line with the basic tenet of the Besley and Coate (1991) argument (i.e. the richer opt out from the public provision). Allowing for 
endogeneity of insurance status is proved to be crucial for answering our research question: under exogeneity, the alternative conclusion would be derived that the more affluent individuals top up, rather than opt out. 


\section{REFERENCES}

Aarbu, K.O., (2010), Demand patterns for treatment insurance in Norway. Cesifo Working Paper No. 3021.

Atella V., Deb P. (2008), Are primary care physicians, public and private sector specialists substitutes or complements? Evidence from a simultaneous equations model for count data. Journal of Health Economics, 27(3), 770-785.

Bath, C.R. (2001), Quasi-random maximum simulated likelihood estimation of the mixed multinomial logit model. Transportation Research: Part B 35, 677-693.

Besley T., Coate S. (1991), Public provision of private goods and the redistribution of income. American Economic Review, 81(4), 979-984.

Besley T., Hall J., Preston I. (1999), The demand for private health insurance: do waiting lists matter?. Journal of Public Economics, 72(2), 155-181.

Buchmuller, T.C, Couffinhal, A., Grignon, M. And Perronin, M. (2004), Access to physician services: does supplemental insurance matter? Evidence from France. Health Economics, 13, 669-687.

Cameron A.C., Trivedi P.K., Milne F., Piggott J. (1988), A microeconometric model of the demand for health care and health insurance in Australia. Review of Economic Studies, 55, 85-106.

Chai Cheng, T, Vahid, F. (2010), Demand for hospital care and private health insurance in a mixed public private system: empirical evidence using a simultaneous equation modeling approach. Health, Econometrics and Data Group (HEDG) Working Papers 10/25, HEDG, c/o Department of Economics, University of York.

Cuff, K., Hurley J., Mestelman S., Muller A., Nuscheler R. (2009), Public and private health care financing with alternate public rationing rules. Forthcoming on Health Economics, DOI: 10.1002/hec.1698.

Davies, P. (1999), The role of health insurance in New Zealand: health insurance in New Zealand. Healthcare Review-Online, n. 3.

Deb P., Trivedi P. (1997), Demand for medical care by the elderly: a finite mixture approach, Journal of Applied Econometrics, 12, 313-336.

Deb P., Trivedi P. (2002), The structure of demand for health care: latent class versus twopart models, Journal of Health Economics, 21, 601-625.

Deb, P., Trivedi, P.K. (2006), Specification and simulated maximum likelihood estimation of a non-normal treatment-outcome model with selection: Application to health care utilization. Econometrics Journal, 9, 307-331.

Epple D., Romano R.E. (1996), Ends against the middle: determining public service provisions when there are private alternatives. Journal of Public Economics 62, 297325.

Fabbri, D., Monfardini, C., (2003), Public vs. private health care services demand in Italy. Giornale degli Economisti 62 (1), 93-123.

Fabbri, D., Monfardini, C. (2009), Rationing the public provision of healthcare in the presence of private supplements: evidence from the Italian NHS. Journal of Health Economics, vol. 28, 290-304.

Foubister, T., Thomson, S., Mossialos, E., McGuire A. (2006), Private medical insurance in the United Kingdom. WHI, European Observatory on Health Systems and Policies.

Gourieroux, C. Monfort, A. (1996), Simulation based econometric methods. Oxford: Oxford University Press. 
Holly, A., Gardiol, L., Domenighetti, G., Bisig, B. (1998), An econometric model of health care utilization and health insurance in Switzerland. European Economic Review 42, 513-522.

Idler, E. and Benyamini, Y. (1997), Self-rated health and mortality: a review of twenty seven community studies. Journal of Health and Social Behavior, 38(1), 21-37.

Mossialos E, Thomson S. (2004), Voluntary health insurance in the European Union. World Health Organization: Geneva.

Munkin, M.K., Trivedi, P.K. (2008), Bayesian analysis of the ordered probit model with endogenous selection, Journal of Econometrics, 143, 334-348.

Pohlmeier W., Ulrich V. (1995), An econometric model of the two-part decision making process in the demand for health care, Journal of Human Resources, 30, 339-61.

Schmitz, H. (2011), Direct evidence on risk aversion as a source of advantageous selection in health insurance, mimeo, Rheinisch-Westfälisches Institut für Wirtschaftsforschung.

Srivastava, P and Zhao, X (2008), Impact of private health insurance on the choice of public versus private hospital services. Health, Econometrics and Data Group (HEDG) Working Papers 08/08, HEDG, c/o Department of Economics, University of York.

Train, K. (2002). Discrete choice methods with simulation. New York: Cambridge University Press.

Zimmer, D.M. and Trivedi, P.K (2006), Using trivariate copulas to model sample selection and treatment effects: application to family health care demand. Journal of Business and Economics Statistics, 24 (1), 63-75. 


\section{TABLES AND Figures}


Table 1: The market for insurance in Italy

\begin{tabular}{lcc}
\hline \hline Our insurance status variable & FREQ & $\%$ \\
\cline { 2 - 3 } NO VHI & 22,074 & $79.0 \%$ \\
NFP VHI only & 2,689 & $9.6 \%$ \\
FP VHI & 3,182 & $11.4 \%$ \\
total & 27,945 & $100.0 \%$ \\
\hline \hline
\end{tabular}

Source: Elaborations on our sample from "Indagine Statistica Multiscopo sulle Famiglie: condizioni di salute e ricorso ai servizi Sanitari 1999-2000".

Table 2: Frequency of specialists visits by type

\begin{tabular}{cccc}
\hline \hline $\mathrm{N}^{\circ}$ Visits & Public Specialist & Private specialist & Any type \\
\cline { 2 - 4 } 0 & $94.5 \%$ & $95.4 \%$ & $90.4 \%$ \\
1 & $4.3 \%$ & $3.7 \%$ & $7.1 \%$ \\
2 & $0.9 \%$ & $0.7 \%$ & $1.7 \%$ \\
3 & $0.2 \%$ & $0.2 \%$ & $0.4 \%$ \\
4 & $0.1 \%$ & $0.1 \%$ & $0.2 \%$ \\
+4 & $0.1 \%$ & $0.0 \%$ & $0.1 \%$ \\
$\mathrm{~N}^{\circ}$ Obs. & & & \\
Positives & 27,945 & 27,945 & 27,945 \\
Participation Rate & 1,543 & 1,295 & 2,682 \\
\hline \hline
\end{tabular}

Source: Elaborations on our sample 
Table 3: Specialists visits \& insurance status in our case study

\begin{tabular}{|c|c|c|c|c|c|c|}
\hline \multirow[b]{2}{*}{ INSURANCE STATUS } & \multicolumn{3}{|c|}{ average \# of visits } & \multicolumn{3}{|c|}{$\%$ of positives } \\
\hline & PUBLIC & PRIVATE & TOTAL & PUBLIC & PRIVATE & TOTAL \\
\hline $\mathrm{NO} \mathrm{VHI}$ & 0.079 & 0.057 & 0.136 & $5.8 \%$ & $4.3 \%$ & $9.6 \%$ \\
\hline FP VHI & 0.054 & 0.083 & 0.137 & $4.0 \%$ & $6.2 \%$ & $9.5 \%$ \\
\hline ALL & 0.075 & 0.061 & 0.136 & $5.5 \%$ & $4.6 \%$ & $9.6 \%$ \\
\hline NFP VHI only & $-0.174^{*}$ & 0.141 & -0.030 & -0.090 & $0.176^{*}$ & 0.037 \\
\hline FP VHI & $-0.382^{* * *}$ & $0.376^{\star * *}$ & 0.007 & $-0.367^{* * *}$ & $0.369^{* * *}$ & -0.005 \\
\hline
\end{tabular}

Source: Elaborations on our sample. ***, **, $*$ denotes significance levels at 1,5 and $10 \%$ respectively. 
Table 4: Regressors of the joint model for visit count and insurance choice

\begin{tabular}{|c|c|c|c|c|}
\hline VARIABLE & & Mean & $\begin{array}{l}\text { Std. } \\
\text { Dev. }\end{array}$ & $\begin{array}{c}\text { Enter which } \\
\text { equation }\end{array}$ \\
\hline \multicolumn{5}{|l|}{ HEALTH } \\
\hline EXEMPT & $=1$ if exempted & 0.17 & 0.38 & ВОTH \\
\hline INVALID & $=1$ if invalid & 0.04 & 0.18 & ВОТН \\
\hline CHRONIC. & $=1$ if any chronic condition & 0.53 & 0.50 & BOTH \\
\hline NCHRONIC & number of chronic conditions & 1.17 & 1.60 & BOTH \\
\hline LIM ADL & $=1$ if any limitation in daily activity & 0.04 & 0.20 & BOTH \\
\hline SRH good & $=1$ if self reported health good or very good & 0.58 & 0.49 & ВОТН \\
\hline \multicolumn{5}{|l|}{ SOCIO-DEMOGRAPHIC } \\
\hline AGE & age (years) & 49.05 & 11.93 & ВОТН \\
\hline AGESQ & age squared/100 & 25.49 & 11.75 & ВОTH \\
\hline MARRIED & $=1$ if married & 0.86 & 0.35 & ВОТН \\
\hline MEDIUM EDUC & $=1$ if secondary school certificate & 0.30 & 0.46 & ВОТН \\
\hline HIGH EDUC & $=1$ if university degree & 0.08 & 0.27 & ВОТН \\
\hline \multicolumn{5}{|l|}{ EMPLOYMENT STATUS } \\
\hline EMPLOYED & $=1$ if employed & 0.70 & 0.46 & ВОТН \\
\hline SELF-EMPL & $=1$ if self-employed & 0.23 & 0.42 & ВОTH \\
\hline HIGH POSITION & $=1$ if high professional position & 0.06 & 0.24 & ВОTH \\
\hline HIGH POSITION SELF-EMPL & $=1$ if high position \& self-employed & 0.08 & 0.26 & ВОТН \\
\hline \multicolumn{5}{|l|}{ ECONOMIC - INDIVIDUAL } \\
\hline INCOME & Monthly equalized family income* & 5.41 & 4.51 & ВОTH \\
\hline HOME OWNERSHIP & $=1$ if house owner & 0.75 & 0.43 & BOTH \\
\hline \multicolumn{5}{|l|}{ ECONOMIC-LHA } \\
\hline PUBLIC EXP & Per capita public health expend. (x 1000 euro) & 0.99 & 0.22 & ВОTH \\
\hline PHYSICIAN DENSITY & Physician density ( $\times 1000$ inhabitants) & 5.21 & 1.41 & ВОTH \\
\hline FEE PUBLIC & Public specialist visit price* & 0.07 & 0.04 & VISITS \\
\hline FEE PRIVATE & Private specialist visit price* & 0.33 & 0.05 & VISITS \\
\hline PRICE NON FOOD BUNDLE & Monthly equalized non food family expenditure* & 1.32 & 0.25 & VISITS \\
\hline WAIT PUBLIC & Weeks for obtaining public specialist visit & 1.84 & 0.70 & VISITS \\
\hline WAIT PRIVATE & Weeks for obtaining private specialist visit & 0.85 & 0.39 & VISITS \\
\hline HIGH DIFF IN WAIT & $=1$ if WAIT PUBLIC - WAIT PRIVATE $>0.8$ & 0.52 & 0.50 & INSURANCE \\
\hline \multicolumn{5}{|l|}{ CONTEXT } \\
\hline CHIEF TOWN & $=1$ if living in a chief town & 0.25 & 0.43 & ВОTH \\
\hline REGIONAL FIXED EFFECTS & 19 dummies, reference group: Lombardia & & & ВОТН \\
\hline \multicolumn{5}{|l|}{ INSTRUMENTS } \\
\hline PREMIUM & Monthly equalized premium for FP VH" ${ }^{*}$ & 8.09 & 1.54 & INSURANCE \\
\hline CHILDREN & $=1$ if have kids below 18 & 0.42 & 0.49 & INSURANCE \\
\hline \#CHILDREN & \# kids below 18 & 0.66 & 0.89 & INSURANCE \\
\hline AGRICULTURE & $=1$ if employed in agriculture & 0.05 & 0.23 & INSURANCE \\
\hline RETAIL TRADE & $=1$ if employed in retail trade & 0.15 & 0.36 & INSURANCE \\
\hline TRANSPORTS & $=1$ if employed in transport sector & 0.06 & 0.23 & INSURANCE \\
\hline PROFESSIONAL SERVICES & $=1$ if employed in professional services & 0.05 & 0.22 & INSURANCE \\
\hline PUBLIC ADMINISTRATION & $=1$ if employed in public administration & 0.08 & 0.27 & INSURANCE \\
\hline EDUCATION & $=1$ if employed in education sector & 0.06 & 0.23 & INSURANCE \\
\hline \multicolumn{5}{|l|}{ ENDOGENOUS DUMMIES } \\
\hline NFP VHI only & $=1$ if doubly insured with NFP VHI only & 0.10 & 0.29 & VISITS \\
\hline $\mathrm{FP} \mathrm{VHI}$ & $=1$ if doubly insured with FP and possibly NFP VHI & 0.11 & 0.32 & VISITS \\
\hline
\end{tabular}

* As a share of LHA food expenditure 
Table 5: Moral hazard and selection effects

\begin{tabular}{|c|c|c|c|c|}
\hline & \multicolumn{2}{|c|}{$\begin{array}{l}\text { EXOGENOUS } \\
\text { INSURANCE }\end{array}$} & \multicolumn{2}{|c|}{$\begin{array}{l}\text { ENDOGENOUS } \\
\text { INSURANCE }\end{array}$} \\
\hline & $\begin{array}{l}\text { PUBLIC } \\
\text { visits }\end{array}$ & $\begin{array}{l}\text { PRIVATE } \\
\text { visits }\end{array}$ & $\begin{array}{l}\text { PUBLIC } \\
\text { visits }\end{array}$ & $\begin{array}{l}\text { PRIVATE } \\
\text { visits }\end{array}$ \\
\hline \multirow[t]{2}{*}{ NFP VHI only } & 0.074 & $0.191^{* * *}$ & $-1.175^{\text {***}}$ & $0.695^{\star * *}$ \\
\hline & $(0.103)$ & $(0.107)$ & $(0.105$ & $(0.125$ \\
\hline \multirow[t]{2}{*}{$\mathrm{FP} \mathrm{VHI}$} & -0.069 & $0.424^{\star * *}$ & $-1.353^{\star \star \star}$ & $0.925^{\star \star *}$ \\
\hline & $(0.112)$ & $(0.096)$ & $(0.117$ & $(0.112$ \\
\hline \multirow[t]{2}{*}{$\lambda_{2 P R I V}$} & \multicolumn{2}{|c|}{1.482} & \multicolumn{2}{|c|}{2.358} \\
\hline & \multicolumn{2}{|c|}{$(0.066)$} & \multicolumn{2}{|c|}{$(0.087)$} \\
\hline \multirow[t]{2}{*}{$\lambda_{1 h}$} & & & $1.586^{* * *}$ & $-2.600^{\star \star *}$ \\
\hline & & & $(0.073)$ & $(0.073)$ \\
\hline
\end{tabular}

Parameters are estimated Simulated Maximum Likelihood with 2000 Halton quasi-random draws. The outcomes density is specified as Poisson-normal mixture. Robust standard errors are in parenthesis. $* * *, * *, *$ denotes significance levels at 1,5 and $10 \%$ respectively. 
Table 6: Demand elasticities under endogeneity of insurance.

\begin{tabular}{|c|c|c|}
\hline & $\begin{array}{c}\text { PUBLIC } \\
\text { VISITS }\end{array}$ & $\begin{array}{c}\text { PRIVATE } \\
\text { VISITS } \\
\end{array}$ \\
\hline NFP VHI only & $-1.175^{\star \star \star}$ & $0.695^{\star \star *}$ \\
\hline FP VHI & $-1.353^{\star \star *}$ & $0.925^{\star \star *}$ \\
\hline EXEMPT & $0.445^{\star * *}$ & 0.257 \\
\hline INVALID & 0.131 & 0.148 \\
\hline CHRONIC. & $0.528^{\star * *}$ & $0.615^{\star \star *}$ \\
\hline NCHRONIC & $0.136^{\star * *}$ & $0.184^{\star * *}$ \\
\hline LIM ADL & $0.542^{* * *}$ & $0.724^{* * *}$ \\
\hline SRH good & $-0.622^{* * *}$ & $-0.615^{\star * *}$ \\
\hline AGE & -1.199 & -1.477 \\
\hline AGESQ & 0.552 & 0.826 \\
\hline MARRIED & 0.027 & 0.083 \\
\hline MEDIUM EDUC & $0.266^{* * *}$ & $0.229^{* * *}$ \\
\hline HIGH EDUC & 0.19 & 0.1 \\
\hline EMPLOYED & 0.139 & $0.217^{*}$ \\
\hline SELF-EMPL & 0.22 & 0.135 \\
\hline HIGH POSITION & $0.288^{*}$ & 0.161 \\
\hline HIGH POSITION SELF-EMPL & -0.007 & -0.063 \\
\hline INCOME & 0.002 & 0.047 \\
\hline HOME OWNERSHIP & $0.136^{*}$ & $0.251^{* * *}$ \\
\hline PUBLIC EXP & 0.089 & 0.099 \\
\hline PHYSICIAN DENSITY & 0.06 & 0.029 \\
\hline FEE PUBLIC & -0.191 & $0.229^{*}$ \\
\hline FEE PRIVATE & 0.126 & 0.048 \\
\hline PRICE NON FOOD BUNDLE & 0.289 & -0.229 \\
\hline WAIT PUBLIC & -0.137 & 0.092 \\
\hline WAIT PRIVATE & -0.088 & $-0.232^{* * *}$ \\
\hline CHIEF TOWN & 0.114 & 0.05 \\
\hline
\end{tabular}

$* * *, * *, *$ denotes significance levels at 1,5 and $10 \%$ respectively. 
Table 7: Average marginal effects of covariates (elast.\&semi-elast.) on insurance choice.

\begin{tabular}{|c|c|c|c|}
\hline & $\begin{array}{l}\text { NO Double } \\
\text { insurance }\end{array}$ & DI with NFP only & DI with FP \\
\hline EXEMPT & 0.013 & -0.019 & -0.073 \\
\hline INVALID & -0.004 & -0.122 & 0.133 \\
\hline CHRONIC. & $-0.034^{* * *}$ & 0.059 & $0.184^{* * *}$ \\
\hline NCHRONIC & -0.003 & 0.037 & -0.006 \\
\hline LIM ADL & 0.010 & -0.034 & -0.038 \\
\hline SRH good & $-0.027^{* * *}$ & 0.071 & $0.125^{\star * *}$ \\
\hline MARRIED & -0.013 & $0.177^{* * *}$ & -0.059 \\
\hline MEDIUM EDUC & $-0.103^{* * *}$ & $0.447^{* * *}$ & $0.337^{* * *}$ \\
\hline HIGH EDUC & $-0.129^{* * *}$ & $0.423^{* * *}$ & $0.537^{* * *}$ \\
\hline EMPLOYED & $-0.146^{* * *}$ & $0.875^{\star * *}$ & $0.274^{\star * *}$ \\
\hline SELF-EMPL & $-0.134^{\star \star *}$ & $0.497^{* * *}$ & $0.511^{* * *}$ \\
\hline HIGH POSITION & -0.017 & -0.053 & $0.162^{\star * *}$ \\
\hline HIGH POSITION SELF-EMPL & $-0.155^{\star \star \star}$ & 0.075 & $1.010^{\star * *}$ \\
\hline INCOME & $-0.012^{* \star *}$ & 0.029 & $0.043^{\star *}$ \\
\hline HOME OWNERSHIP & $-0.061^{* * *}$ & $0.188^{* * *}$ & $0.262^{* \star *}$ \\
\hline PREMIUM & $0.317^{\star \star \star}$ & $-0.694^{\star *}$ & $-1.787^{\star \star *}$ \\
\hline PUBLIC EXP & 0.025 & 0.227 & $-0.352^{* *}$ \\
\hline PHYSICIAN DENSITY & $0.073^{* * *}$ & $-0.218^{* *}$ & $-0.340^{* * *}$ \\
\hline HIGH DIFF IN WAIT & $-0.021^{\star *}$ & $0.134^{\star * *}$ & 0.029 \\
\hline CHIEF TOWN & -0.008 & 0.049 & 0.016 \\
\hline
\end{tabular}

$* * *, * *, *$ denotes significance levels at 1,5 and $10 \%$ respectively. 
Table 8: AME of being 1 year older on insurance choice.

\begin{tabular}{lccc}
\hline \hline & $\begin{array}{c}\text { NO Double } \\
\text { insurance }\end{array}$ & $\begin{array}{c}\text { DI with NFP } \\
\text { only }\end{array}$ & DI with FP \\
\cline { 2 - 4 } At age $=20$ & 0.0024 & $0.0016^{* * *}$ & -0.0040 \\
At age $=30$ & 0.0012 & $0.0025^{* * *}$ & -0.0036 \\
At age $=40$ & -0.0004 & $0.0037^{* *}$ & -0.0033 \\
At age $=50$ & -0.0022 & 0.0051 & -0.0029 \\
At age $=60$ & -0.0042 & 0.0067 & $-0.0025^{\star *}$ \\
\hline \hline
\end{tabular}

$* * *, * *, *$ denotes significance levels at 1,5 and $10 \%$ respectively. 
Table 9: Opt out vs. top up.

\begin{tabular}{|c|c|c|c|c|}
\hline \multirow{2}{*}{ PUBLIC visits } & \multicolumn{2}{|c|}{ Under Exogeneity } & \multicolumn{2}{|c|}{ Under Endogeneity } \\
\hline & Income & House own & Income & House own \\
\hline Direct effect & $0.00 \%$ & $7.50 \%$ & $0.20 \%$ & $13.60 \%$ \\
\hline Indirect effect via NFP VHI & $0.20 \%$ & $1.40 \%$ & $-3.40 \%$ & $-22.10 \%$ \\
\hline Indirect effect via FP VHI & $-0.30 \%$ & $-1.80 \%$ & $-5.80 \%$ & $-35.40 \%$ \\
\hline Total effect & $-0.10 \%$ & $7.10 \%$ & $-9.00 \%$ & $-43.90 \%$ \\
\hline \multicolumn{5}{|l|}{ PRIVATE visits } \\
\hline & Income & House own & Income & House own \\
\hline Direct effect & $0.90 \%$ & $25.60 \%$ & $4.70 \%$ & $25.10 \%$ \\
\hline Indirect effect via NFP VHI & $0.60 \%$ & $3.60 \%$ & $2.00 \%$ & $13.10 \%$ \\
\hline Indirect effect via FP VHI & $1.80 \%$ & $11.10 \%$ & $4.00 \%$ & $24.20 \%$ \\
\hline Total effect & $3.30 \%$ & $40.30 \%$ & $10.70 \%$ & $62.40 \%$ \\
\hline
\end{tabular}


Table A1: Model estimates

\begin{tabular}{|c|c|c|c|c|}
\hline \multirow{3}{*}{ NFP VHI only } & \multicolumn{2}{|c|}{ DOUBLY INSURED WITH } & \multicolumn{2}{|c|}{ VISITS COUNT } \\
\hline & $\begin{array}{c}\text { NFP VHI } \\
\text { only }\end{array}$ & FP VHI & PUBLIC & PRIVATE \\
\hline & & & $\begin{array}{c}-1.175^{\star \star \star} \\
0.105\end{array}$ & $\begin{array}{c}0.695^{\star \star \star} \\
0.125\end{array}$ \\
\hline \multirow[t]{2}{*}{ FP VHI } & & & $-1.353^{\star \star \star}$ & $0.925^{\star \star *}$ \\
\hline & & & 0.117 & 0.112 \\
\hline \multirow[t]{2}{*}{ EXEMPT } & -0.055 & -0.109 & $0.445^{\star *}$ & 0.257 \\
\hline & 0.081 & 0.079 & 0.174 & 0.179 \\
\hline \multirow{2}{*}{ INVALID } & -0.121 & 0.135 & 0.131 & 0.148 \\
\hline & 0.162 & 0.141 & 0.123 & 0.147 \\
\hline \multirow[t]{2}{*}{ CHRONIC } & $0.118^{*}$ & $0.238^{* * *}$ & $0.528^{* * *}$ & $0.615^{\star * *}$ \\
\hline & 0.066 & 0.063 & 0.086 & 0.090 \\
\hline \multirow[t]{2}{*}{ NCHRONIC } & 0.037 & 0.002 & $0.116^{\star * *}$ & $0.158^{* * *}$ \\
\hline & 0.024 & 0.023 & 0.019 & 0.021 \\
\hline \multirow{2}{*}{ LIM ADL } & -0.065 & -0.063 & $0.542^{* \star *}$ & $0.724^{\star * *}$ \\
\hline & 0.155 & 0.148 & 0.104 & 0.124 \\
\hline \multirow[t]{2}{*}{$\mathrm{SRH}$ good } & $0.121^{\star \star}$ & $0.165^{\star \star \star}$ & $-0.622^{* \star *}$ & $-0.615^{\star \star \star}$ \\
\hline & 0.055 & 0.053 & 0.073 & 0.075 \\
\hline \multirow[t]{2}{*}{ AGE } & 0.048 & -0.024 & -0.024 & -0.030 \\
\hline & 0.031 & 0.031 & 0.021 & 0.026 \\
\hline \multirow[t]{2}{*}{ AGESQ } & -0.058 & 0.022 & 0.022 & 0.032 \\
\hline & 0.036 & 0.036 & 0.022 & 0.027 \\
\hline \multirow{2}{*}{ MARRIED } & $0.213^{* \star *}$ & -0.020 & 0.027 & 0.083 \\
\hline & 0.074 & 0.068 & 0.088 & 0.099 \\
\hline \multirow[t]{2}{*}{ MEDIUM EDUC } & $0.636^{* * *}$ & $0.535^{\star * *}$ & $0.266^{\star * *}$ & $0.229^{* * *}$ \\
\hline & 0.054 & 0.053 & 0.076 & 0.080 \\
\hline \multirow[t]{2}{*}{ HIGH EDUC } & $0.659^{* \star *}$ & $0.786^{\star * *}$ & 0.190 & 0.100 \\
\hline & 0.100 & 0.091 & 0.158 & 0.143 \\
\hline \multirow[t]{2}{*}{ EMPLOYED } & $1.113^{* * *}$ & $0.502^{* * *}$ & 0.139 & $0.217^{*}$ \\
\hline & 0.113 & 0.111 & 0.092 & 0.115 \\
\hline \multirow[t]{2}{*}{ SELF-EMPL } & $0.351^{* * *}$ & $1.293^{* * *}$ & -0.007 & -0.063 \\
\hline & 0.070 & 0.066 & 0.105 & 0.104 \\
\hline \multirow{2}{*}{ HIGH POSITION } & $0.744^{\star * \star}$ & $0.758^{\star \star \star}$ & 0.220 & 0.135 \\
\hline & 0.089 & 0.093 & 0.163 & 0.143 \\
\hline \multirow[t]{2}{*}{ HIGH POSITION SELF-EMPL } & -0.010 & $0.200^{\star *}$ & $0.288^{*}$ & 0.161 \\
\hline & 0.100 & 0.081 & 0.151 & 0.141 \\
\hline \multirow[t]{2}{*}{ INCOME } & $0.008^{*}$ & $0.011^{\star \star}$ & 0.000 & 0.009 \\
\hline & 0.005 & 0.004 & 0.007 & 0.006 \\
\hline HOME OWNERSHIP & $0.291^{* * *}$ & $0.365^{\star * *}$ & 0.136 & $0.251^{* * *}$ \\
\hline & 0.057 & 0.056 & 0.073 & 0.083 \\
\hline PUBLIC EXP & 0.177 & -0.423 & 0.090 & 0.100 \\
\hline & 0.196 & 0.190 & 0.239 & 0.275 \\
\hline PHYSICIAN DENSITY & $-0.064^{\star * *}$ & $-0.089^{* * *}$ & 0.012 & 0.005 \\
\hline & 0.024 & 0.022 & 0.031 & 0.033 \\
\hline FEE PUBLIC & & & -2.599 & $3.105^{\star}$ \\
\hline & & & 1.803 & 1.702 \\
\hline FEE PRIVATE & & & 0.386 & 0.147 \\
\hline & & & 0.738 & 0.823 \\
\hline PRICE NON FOOD BUNDLE & & & 0.220 & -0.173 \\
\hline & & & 0.199 & 0.229 \\
\hline WAIT PUBLIC & & & -0.075 & 0.050 \\
\hline & & & 0.061 & 0.068 \\
\hline WAIT PRIVATE & & & -0.103 & $-0.271^{\star \star *}$ \\
\hline & & & 0.089 & 0.100 \\
\hline
\end{tabular}


Table A1: Model estimates. Continues...

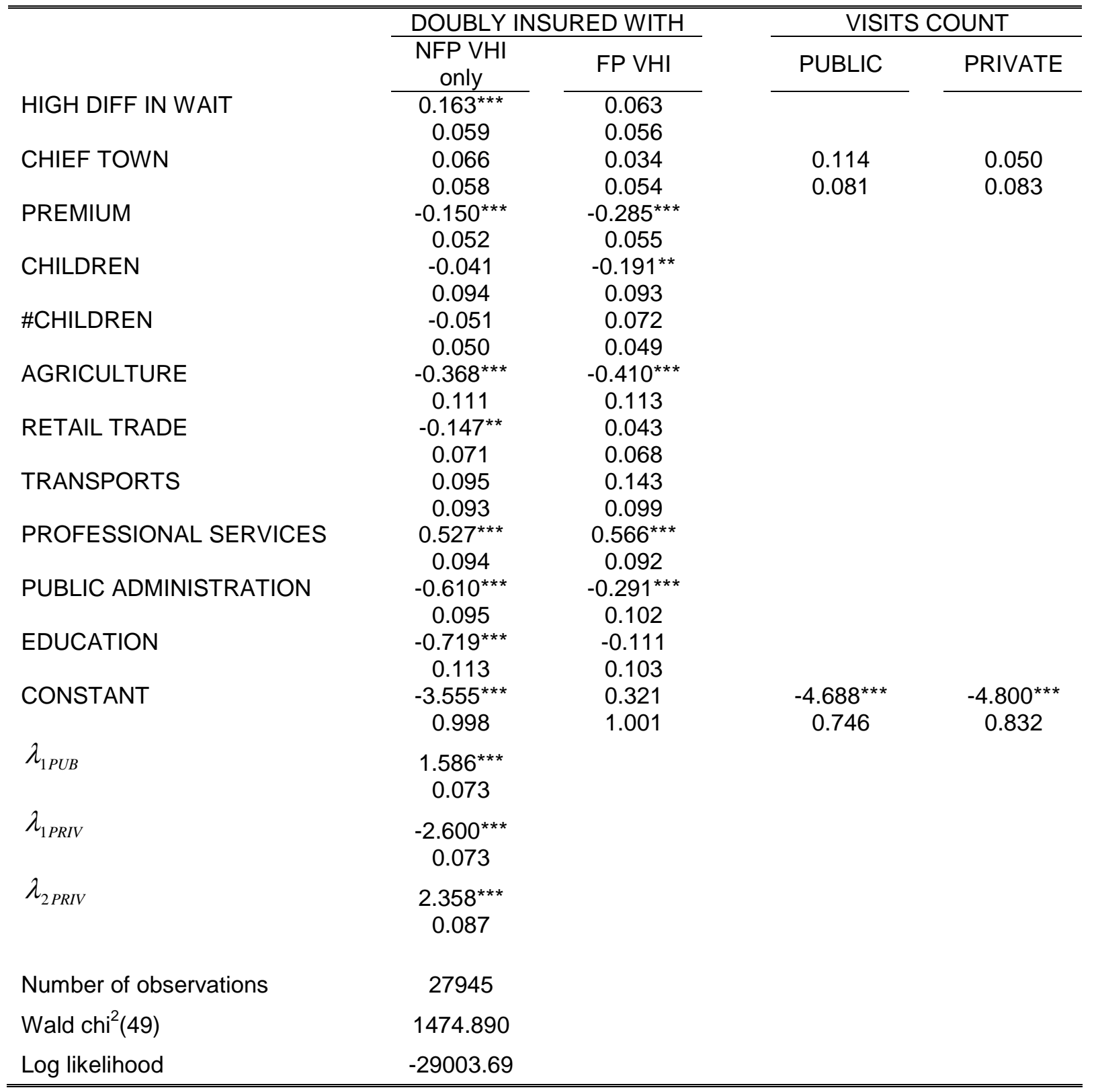




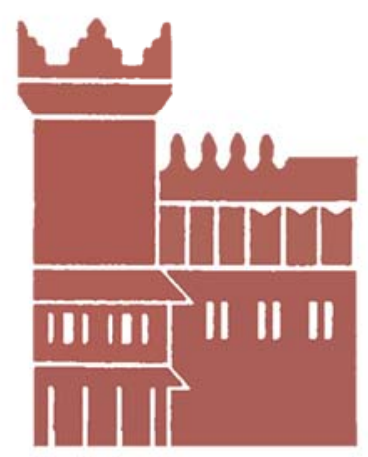

Alma Mater Studiorum - Università di Bologna DEPARTMENT OF ECONOMICS

Strada Maggiore 45

40125 Bologna - Italy

Tel. +39051 2092604

Fax +390512092664

http://www.dse.unibo.it 